\title{
Um Iluminismo libertino
}

\author{
Breno Ferraz Leal Ferreira*
}

Nunes, Rossana Agostinho. Nas sombras da libertinagem: Francisco de Mello Franco (1757-1822) entre Luzes e Censura no mundo luso-brasileiro. Rio de Janeiro: Editora Multifoco, 2013.

Aquele que comprar o livro de Rossana Agostinho Nunes esperando encontrar um simples trabalho sobre Francisco Mello Franco (1757-Paracatu - 1822-Ubatuba) cometerá um equívoco. Nas sombras da libertinagem: Francisco de Mello Franco (17571822) entre Luzes e Censura no mundo luso-brasileiro, mais do que uma obra sobre o polêmico médico luso-brasileiro, é uma reflexão acerca da sociedade e do mundo intelectual em que o personagem em questão estava inserido.

Resultado da publicação de sua dissertação de mestrado defendida na Universidade Federal Fluminense (2011) sob orientação de Guilherme Pereira das Neves, o livro traz nove capítulos divididos em três partes que esquadrinham uma série de problemáticas relacionadas com a cultura das Luzes portuguesas a partir da análise das polêmicas que envolveram o nome de Mello Franco entre as últimas décadas do século XVIII e o início do XIX. Baseada em extensa pesquisa de fontes e bibliografia, a obra é muito bem escrita e coloca de maneira bastante clara os problemas levantados.

Embora se trate de uma obra que vai muito além da vida e dos escritos de Mello Franco, é necessário que se adiante aqui alguns traços de sua biografia. Tendo nascido em Paracatu, Minas Gerais, e emigrado para Portugal ainda jovem, formou-se médico na Universidade de Coimbra, onde foi também condenado e preso pela Inquisição sob a acusação de libertinagem. Foi autor de obras como Tratado da educação física dos meninos (1790) e Elementos de higiene (1814), entre outras. Teve quatro obras cuja autoria lhe foi atribuída, entre as quais a Medicina teológica (1794), escrito sobre o qual se trata o livro de Rossana Nunes.

Antes de chegar propriamente às polêmicas em torno da obra Medicina teológica, analisada na terceira parte da obra, Nunes optou por discutir aspectos necessários para fundamentar seus argumentos a respeito desta obra nas duas primeiras: a questão da libertinagem no Iluminismo português, na primeira, e a estratégia do anonimato necessária para a publicização de determinadas ideias naquele contexto envolto pela censura, na segunda.

A primeira parte, denominada "Contra a revolução doutrinária e doutrinal: o ima-

\footnotetext{
* Doutorando em História Social pela Universidade de São Paulo (USP). São Paulo, SP, Brasil. E-mail: brenoferreira@usp.br.
} 
ginário de uma repressão", tem entre seus objetivos analisar a razão pela qual entre os personagens das últimas décadas do século XVIII estabeleceu-se uma relação de causa e efeito entre ideias libertinas e revolução, num nexo que era compreendido praticamente como uma fatalidade. Nesse sentido, a autora se detém sobre o conceito de libertinagem (entendido em geral como relacionado com a ideia de irreligião) e livros de autores considerados libertinos daquele contexto. São elencados autores acusados à época como libertinos, como o dicionarista António de Morais Silva (1755-1824) e o matemático José Anastácio da Cunha (1744-1787), além do próprio Mello Franco. Ao mesmo tempo, são relacionadas tanto leis que, desde o período pombalino, proibiam a circulação de obras consideradas libertinas, quanto depoimentos de personagens que condenaram ideias consideradas heterodoxas, especialmente as provindas da França.

Chega-se, assim, à questão que norteia o pensamento da autora: por qual motivo e como se formou no imaginário de alguns indivíduos a conexão entre libertinagem e revolução? Trata-se de um imaginário constituído antes mesmo da irrupção da Revolução na França. Nos dizeres de Nunes, “a eclosão da Revolução Francesa e seus desdobramentos, interpretadas por muitos como um dos efeitos da difusão das novas ideias filosóficas do século, trouxe ao primeiro plano a associação entre livre-pensamento, irreligiosidade e sedição" (p. 53). Em outras palavras, a Revolução consolidou essa associação já anteriormente existente.
Nesse ponto entra a discussão em torno de uma das obras atribuídas a Francisco de Mello Franco. Em 1794, veio à luz anonimamente a obra Medicina teológica, que apesar de ter recebido o aval para publicação por parte da censura, causou alvoroço e queixas por parte do público e por isso foi retirada de circulação. Logo depois, optou-se por uma reformulação do sistema de censura então em vigor, extinguindo-se a Real Mesa da Comissão Geral sobre Exame e Censura de Livros (criada em 1787) e estabelecendo-se um retorno, com essa medida, ao antigo sistema de censura tríplice (Santo Ofício, Desembargo do Paço e episcopado). Coincidentemente ou não, no mesmo dia em que essa mudança foi instituída, o Intendente de Polícia, Diogo Inácio de Pina Manique (1733-1805), emitiu um relatório sobre o livro, no qual se referia a ele como uma ameaça à religiáo e ao trono. Manique pensava que o combate às ideias libertinas seria uma condição para a preservação da ordem calcada na Igreja e no Estado.

Autor anteriormente condenado à prisão por libertinagem quando estudante de medicina da Universidade de Coimbra, Mello Franco foi acusado de ser o responsável pela obra, muito embora nunca tivesse assumido sua autoria. É o que a autora mostra na segunda parte do livro, intitulada "Sob o véu do segredo: leituras anônimas de um suposto autor".

Sem poder garantir ser Mello Franco o verdadeiro autor de tais obras, a autora acertadamente opta por fazer nesta parte do livro uma discussão sobre a circulação de obras anônimas e de estratégias utilizadas, 
supostamente ou não, por Mello Franco, tanto para fugir à censura quanto para ascender socialmente na sociedade portuguesa de finais de Antigo Regime.

Dessa forma, Nunes apresenta as quatro obras que foram atribuídas a Mello Franco: O reino da estupidez (1785), Resposta ao filósofo solitário (1787), Resposta segunda ao filósofo solitário (1787) e Medicina teológica (1794). Confrontando os argumentos presentes em todas elas com os argumentos desenvolvidos por ele em suas obras autorais, a autora nos deixa praticamente convencidos de que ele é mesmo o verdadeiro autor, já que não foram encontradas contradições quanto às suas ideias. De maneira geral, nas obras são defendidos princípios em comum, que podem ser entendidos como modernos, isto é, a "defesa das ciências naturais, do experimentalismo, do racionalismo e a crítica a um pensamento baseado na autoridade e na superstição" (p. 106), além de outros temas específicos tipicamente ilustrados como a sociabilidade natural do homem e a perfectibilidade. Mais importante ainda, as concepçóes médicas apresentadas estão afinadas com o pensamento médico estrangeiro da época.

Mas mesmo se a hipótese de o polêmico médico não ter sido o verdadeiro autor de tais obras for verdadeira, em nada se invalida as reflexóes da autora. $\mathrm{O}$ anonimato é uma estratégia para fugir aos órgãos de censura e compartilhar na esfera pública ideias tidas como perigosas, que muitas vezes eram bastante aceitas pelo público letrado naquele contexto. Ao mesmo tempo, é analisada a trajetória de Mello Franco, que embora anteriormente condenado como autor liber- tino, galgou importantes cargos dentro daquela sociedade que ainda operava de acordo com a lógica da distribuição de mercês. Ele foi médico do rei, deputado extraordinário da Real Junta do Proto-Medicato e chegou a vice-secretário da Academia das Ciências de Lisboa (e membro ativo de sua instituição vacínica, relativa à pesquisa sobre a vacina contra a varíola). Em 1817, foi escolhido para acompanhar a princesa $\mathrm{D}$. Leopoldina ao Brasil, como médico particular. Em função de seus serviços prestados, conseguiu, a seu pedido, que fosse dado o hábito da Ordem de Cristo com a respectiva tença para o seu filho primogênito, também médico, e outros privilégios para o seu segundo filho. No período final de sua vida, no Brasil, o médico parece ter vivido uma situação precária em função da perda de sua fortuna, o que possivelmente tem a ver com um suposto envolvimento numa conspiração contra o rei (sinal de libertinagem?), como aponta parte da bibliografia, mas que pela ausência de documentos a respeito não pôde ser confirmado pela autora. Teria vivido em uma situação de precariedade até a sua morte, em 1822.

Analisada a trajetória de Mello Franco como autor (real e suposto), coube a Nunes fazer a conexáo entre as discussóes presentes nas duas primeiras partes, na terceira parte da obra, denominada "Diálogos em torno da obra Medicina Theologica”. É nesse momento que fica explicado todo o rebuliço que se deu entorno dessa publicação. A autora descortina as reaçóes que a obra suscitou, inclusive a de Pina Manique, à qual já nos referimos. As outras vieram do viajante francês Carrère (1740-1802), que a entendeu a $\mathrm{Me}$ - 
dicina teológica como libertina ("impregnada de materialismo”, “de proposiçóes equívocas", "livro verdadeiramente perigoso"); e do frei Manuel de Santa Anna, que publicou uma resposta à mesma obra chamada Dissertaçóes teológicas medicinais (1799), na qual o seu autor é condenado por "dogmatismo".

Para explicar tais reaçôes, a autora busca identificar as influências literárias na composição da obra analisada. A partir de uma pesquisa de fôlego, a autora mostra uma série de semelhanças da Medicina teológica com importantes livros de médicos estrangeiros: os franceses Le Camus (1722-1772) e Le-Cat (1700-1768) e o suíço Tissot (17281797). Fica claro que o autor, além de estar atualizado com a literatura médica da época (estando boa parte dela contida nos programas da faculdade de medicina da reformada Universidade de Coimbra), incorporou tais influências de maneira criativa, inserindo reflexóes próprias que constituem, na verdade, a própria causa da reação negativa que recebeu.

A chave para a compreensão da polêmica é que ela altera a maneira como, dentro do quadro intelectual das Luzes portuguesas, está equacionada a relação entre ciência e religião. Mostrando como a obra está inserida num matiz de pensamento que não opera segundo a concepção consagrada pela historiografia de Iluminismo católico, o autor da Medicina teológica, ainda que não fosse assumidamente um autor não católico, nem mesmo irreligioso, argumentava que distúrbios físicos e corporais como a cólera e a lascívia (responsável pela luxúria) somente poderiam ser curados por remédios prescritos pelos médicos. Os padres deveriam ter conhecimentos médicos para prescrevê-los no ato da confissão. Ou seja, como muito bem interpreta Nunes, tratava-se de uma tentativa de "racionalizar o sacramento da confissão” (p. 144), o que transformava o autor em "dogmatista", acusação que já anteriormente fora imputada a Mello Franco, na ocasião do processo inquisitorial que o levou à prisão.

Dado, portanto, que os pecados náo passavam de doenças corporais, caía por terra a importância da graça divina e o ensinamento do Evangelho. Podendo ser identificado como um autor deísta, o autor anônimo minimizava a importância do sobrenatural, não só dando soluções basicamente imanentes para remediar problemas físicos, mas também afirmando que os próprios confessores deveriam avançar no conhecimento desse domínio da razão. Dessa forma, Nunes propóe que a obra altera a maneira como tradicionalmente a razão era entendida dentro do pensamento setecentista português, citando, como exemplo, o padre oratoriano Teodoro de Almeida (1722-1804), grande valorizador da filosofia experimental em Portugal na segunda metade do século XVIII, mas para quem o conhecimento do mundo físico era uma "prova da omnipotência de Deus" (p. 119). Para o autor da Medicina teológica, os atributos divinos da razão deixam de ser uma questão.

Por se tratar de uma obra sobre medicina, talvez tivesse sido o caso de a autora ter inserido a Medicina teológica no contexto mais amplo do pensamento médico ilustrado português mais detidamente. Pensamos particularmente nas concepções de Antônio Nunes 
Ribeiro Sanches (1699-1783), formulador de uma concepção de saber médico que, entre outras características, entendia as paixóes humanas como parte da natureza. Nesse sentido, parece haver um leque de sentidos comuns entre suas obras, as de Mello Franco e a obra em questáo. Não custa lembrar que os novos Estatutos da Universidade (1772), os quais instituíram uma concepção de saberes secularizados, i.e., baseados na razão, foram, em larga medida, influenciados pelas ideias modernizantes de Ribeiro Sanches.

Outra crítica que pode ser feita à obra é que poderia ficar mais bem explicitado no desenvolvimento do livro o que exatamente mudou na política do Estado português em relação às obras consideradas heterodoxas após a Revolução Francesa. Como a autora deixa bem claro, anteriormente já havia uma política repressiva empregada pelo aparelho estatal que buscava coibir a circulação de obras consideradas perigosas. Diz Nunes: "Neste novo cenário [da morte do rei francês], posturas consideradas incrédulas e críticas em relação à religiáo náo podiam mais ser toleradas" (p. 124). Ora, mas para além do retorno à censura tríplice, do relatório de Pina Manique e da ordem de retirada de circulação da Medicina teológica, em 1794, não são apresentados mais dados que corroborem a ideia de uma mudança de política. Enriquecer-se-ia ainda mais a obra se fossem apresentadas mais informaçóes sobre a ação repressiva às ideias consideradas libertinas, não só no período de Pina Manique enquanto intendente geral de polícia, mas durante toda a vida de Mello Franco, que inclui, não custa lembrar, a invasão de Portugal pelas tropas napoleônicas, a ida da Corte ao Brasil e a Revoluçáo de 1820.

Ainda sobre a formação de um imaginário que relacionava a difusão de ideias libertinas à ruptura da ordem institucional, existente em Portugal já anteriormente a 1789 - questão essa muito bem elaborada pela autora e com a qual concordamos pensamos que a tese poderia ser mais bem corroborada pela documentaçáo arrolada nas fontes se utilizasse mais o livro do frade franciscano José Mayne (1723-1792), Dissertação sobre a alma racional (1778), pouco usado pela autora. O livro de Mayne, além de se tratar de possivelmente a obra mais incisiva escrita contra a libertinagem em Portugal setecentista, constitui um dos melhores exemplos, senão o melhor, de obras que relacionam as ideias libertinas como perigosas ao mesmo tempo à religiáo e ao Estado, e isso cerca de onze anos antes da eclosão da sedição na França.

Por fim, dado que o impacto da Revolução Francesa no patrulhamento às ideias ditas libertinas (e muitas vezes associadas à expressão "jacobinas" na documentação portuguesa) é um dos temas centrais da dissertação, cabe fazer uma pequena correção factual. Afirma-se à página 21 que a morte do rei Luís XVI foi conduzida pelo terror jacobino, informação repetida à página $57 . \mathrm{Na}$ verdade, os jacobinos ascenderam ao poder em meados de 1793, quando o rei francês já havia sido guilhotinado (janeiro do mesmo ano). Porém, isso em nada diminui os méritos de uma publicação que capta muito bem os sentidos e os caminhos de uma sociedade e do mundo intelectual português e 
luso-brasileiro de uma época de profundas transformaçôes.

Em suma, pode-se dizer que a obra de Rossana Agostinho Nunes discute, de forma muito bem escrita, problemas que contribuem de maneira importante, mais do que para a compreensão da trajetória e do sentido da obra de Francisco de Mello Franco, para a compreensão das Luzes luso-brasileiras setecentistas. São examinadas, entre outros aspectos, a presença e a função de obras li- bertinas nos contextos anterior e posterior à Revolução Francesa, a questão da necessidade do anonimato para a emergência das mesmas ideias, as condiçóes que permitiam a mobilidade em uma sociedade na qual ainda persistia uma lógica baseada na distribuição de mercês (embora em profunda transformação) e, talvez o que seja o mais importante, a formaçáo de um Iluminismo secularizado, no qual a razáo, se desprendendo de uma tutela religiosa, atingia maior autonomia. 